\title{
Research on Electric-Vehicle Switching Scheduling and Charging Strategy of Charging Stations
}

\author{
Yuxing $\mathrm{Li}^{1}$, Hao $\mathrm{Wu}^{2}, \mathrm{Yu} \mathrm{Shi}^{1}$, Hao $\mathrm{Li}^{1}$, Xuefeng $\mathrm{Gao}^{1}$, Yeyang $\mathrm{Zhu}^{3, *}$, \\ ${ }^{1}$ State Grid Economic And Technical Research Institute Of Jilin Electric Power.,LTD \\ ${ }^{2}$ Hangzhou Power Supply Company of State Grid Zhejiang Electric Power Company \\ ${ }^{3}$ University of Southern California
}

\begin{abstract}
In order to effectively alleviate the congestion of power exchange stations, the game theory was used to discuss the spatial characteristics of electric vehicle power exchange demand, analyze the decision making and game process of electric vehicle users specifically. Moreover, on the basis of the research, the specific way of setting the price of the exchange station was proposed and the game mathematical model was constructed.
\end{abstract}

\section{Preface}

At present, the promotion and use of electric vehicles have encountered two major problems of electric vehicle charging. The electricity can quickly be replenished and it is difficult to achieve centralized charging and discharging in the charging mode due to the randomness of charging of drivers. Incentive strategies are especially needed to be adopted to guide users to charge, as a way to adjust the peak load. According to the above problems, the power-exchanging mode for power exchange stations, which spotlighted recent years, was especially proposed. This mode cannot only meet the electricity demand of charging vehicles, but also realize the centralized management and maintenance of the replaced batteries, thereby reducing the burden on users. Therefore, this paper mainly studied to meet the needs of drivers to replace the battery while minimizing the charging cost.

\section{Technology of Switching Scheduling}

\subsection{Charging Mode of Electric vehicle}

At present, the charging modes can be divided into three methods, which are ordinary Alternating Current charging, fast Direct current charging and the power exchange mode. Among them, the first two methods are the most common. Thus, these two charging methods will be briefly introduced in this paper.

\subsubsection{Ordinary alternating current charging method}

Alternating current charging mode has a long charging cycle with relatively low cost of charger selection and installation. Compared with fast charging, the cost of alternating current charging is lower, so it is widely used in the market now. During the charging process, the alternating current charging current and power are low, so the damage to the car battery is relatively low. Charging during off-peak power consumption can also reduce the charging cost. But it needs to be clarified that the charging cycle of the alternating current charging is longer, so in emergency situations, it is difficult to meet the needs of users.

\subsubsection{Fast charging}

Battery charging is time-consuming and incontinent when charging outside. To cut the charging time effectively, it is necessary to reduce the polarization of the positive and negative electrodes of the battery. On the premise of not destroying the capacity of battery, it is necessary to improve the efficiency of the battery. Countries are now studying to improve the efficiency of rapid charging while charging. Fast charging refers to the use of a relatively large current to complete the charging of electric vehicles in a short time. However, this will cause a huge impact on the grid due to the existence of strong currents, thereby affecting the battery life. ${ }^{[1]}$

\subsubsection{Battery Switching Mode}

Unlike the previous two modes, battery switching mode can supplement the electric energy efficiently, by renting a fully charged battery and directly replacing it to the vehicle that has run out of electric energy, and the battery pack will be charged uniformly at non-peak hours, so as to reduce the cost of charging and also improve the efficiency of vehicle use. The whole operation usually takes about 10 minutes,

Although this mode has outstanding advantages but battery exchange mode can only be used as a transitional

* Corresponding author: yeyangzh@usc.edu 
program in a certain period for the current development of charging technology. And it is mainly used for electric buses for the application of higher regularity and a relatively large amount of travel mileage.

\subsection{Driving Habits of Electric Vehicle Users}

According to the research on the operating time and charging mode of electric vehicles for three different purposes, namely, buses, taxis and private cars, results are as shown in the table.

Table 1. The running time and charging mode of three kinds of electric vehicles

\begin{tabular}{|l|c|c|c|}
\hline $\begin{array}{l}\text { Type of } \\
\text { electric } \\
\text { vehicles }\end{array}$ & Bus & Taxi & Private Car \\
\hline $\begin{array}{l}\text { Operating } \\
\text { hours }\end{array}$ & $6 \mathrm{am}-10 \mathrm{pm}$ & All day & $\begin{array}{c}\text { Irregularly, } \\
\text { mainly during } \\
\text { the day }\end{array}$ \\
\hline $\begin{array}{l}\text { Average } \\
\text { daily } \\
\text { mileage }\end{array}$ & $200 \mathrm{~km}$ & $300-500 \mathrm{~km}$ & $20-80 \mathrm{~km}$ \\
\hline $\begin{array}{l}\text { Charging } \\
\text { method } \\
\text { charging } \\
\text { (slow } \\
\text { charging)/S } \\
\text { witching of } \\
\text { Battery }\end{array}$ & $\begin{array}{l}\text { Switching } \\
\text { of Battery }\end{array}$ & $\begin{array}{l}\text { Evening } \\
\text { charging (slow } \\
\text { charging)/Fast } \\
\text { charging/Switc } \\
\text { hing of battery }\end{array}$ \\
\hline
\end{tabular}

According to the data, the route and operating hours of buses are regular, and buses are relatively busy in the peak hours, for this reason drivers will only choose the slow charging method in the off-peak hours. The charging time is concentrated in the period of 10:00 pm 4:00 pm, or 10:00 pm to 6:00 am the next day. And if the night charging cannot meet the needs of the bus during the day, witching battery can also be helpful. ${ }^{[2]}$

Because of the irregular and random parking of the taxi, the taxi driver will choose the nearest charging station or exchange station. Since slow charging will consume a lot of time and cannot meet need of the working taxi, the way of battery switching is more suitable, so that the taxi can be recharged in time.

Private cars are mainly used as basic transportation tools, the purposes are diverse, such as daily commuting, picking up and dropping off children, etc. The most common charging method for private cars is slow charging, followed by fast charging. At present, there are charging piles in the community and parking lot, and the charging time is usually arranged at work and night. Due to different models, it is difficult to change the battery for certain brands of vehicles, so exclusive charging stations are set up. ${ }^{[3]}$

\subsection{Charging process and the basic structure of the charging station}

\subsubsection{Basic structure of the charging station}

The current composition of the station includes information module, charging module and battery switching module, etc. Among them, the charging module is used to charge the battery, the power exchange module is mainly responsible for battery replacement, the energy module is used to receive power depletion reminder and convey the battery change instruction and pass it to the battery switching module. There is a monitoring module and fault module in the station so as to facilitate real-time monitoring of the system operation, and if a fault occurs, the fault module can overhaul and repair the faulty battery.

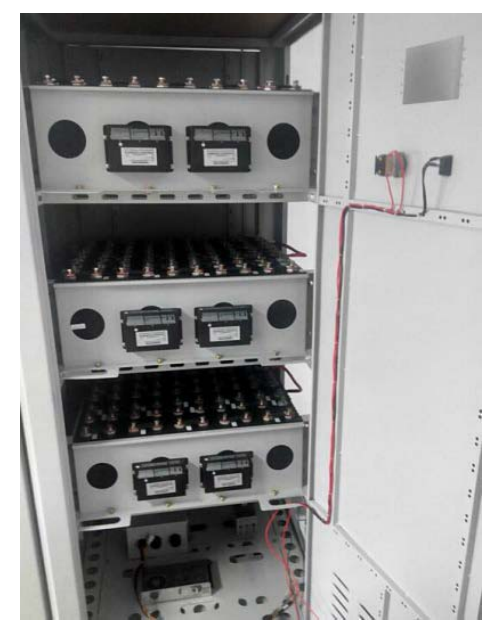

Fig 1. Diagram of the battery switching station

\subsubsection{Battery Replacement}

When replacing the battery, the on-board intelligent instrumentation will automatically search for a replacement station close to the electric car according to the current car mileage, and make an automatic reservation according to the price and driving distance of the replacement station; it will upload the demand for battery replacement, transfer the location information of the reservation, the required battery type and power to the nearby replacement station information module. The power management module of the charging station will replace the battery, and put the user's replaced battery in the charging module for subsequent unified charging according to the specific demand of users. ${ }^{[4]}$

\section{Electric vehicle power charging scheduling method based on Game Theory}

\subsection{Analysis of the spatial characteristics of power charging demand}

\subsubsection{Game Theory}

Game refers to the process in which several decisionmaking subjects choose the most suitable strategy from different feasible strategies. In the process, participants, strategy and payment (income) are involved. And the 
participants are the entities that can make decisions in the game, the participants can be individuals, teams or nature, etc., and $\mathrm{N}=\{1,2, \ldots \mathrm{n}\}$ serve as participants in the game; strategy emphasizes the participants can choose options, the current participants can choose a variety of options, if take $\mathrm{Si}$ as a pure strategy set of participants, when there is a participant exists, the corresponding specific strategy combinations include $\mathrm{s}=\left(\mathrm{s}_{1}, \mathrm{~s}_{2}, \ldots . \mathrm{s}_{\mathrm{n}}\right)$; payment (or income) which is the goal of the participants in the game. The goal of the participants is mainly to minimize the payment or a great gain, and the specific combination of the form is ui(s).

\subsubsection{Game theory assumptions}

Game theory usually includes two assumptions, rationality and public knowledge, the former refers to the participants' tendency to choose the solution that can bring them the greatest benefit or the least expense, and the latter refers to the ability to empower each participant to acquire knowledge and make logical inferences.

\subsubsection{Analysis of the spatial characteristics of power charging demand}

The driver will be influenced by various factors, such as the cost of battery replacement, the distance between the current driving distance and the target station, the distance between the station and the next target location, and whether the user's current remaining power can reach the target exchange station, whether the user needs to queue up for the exchange station, and if so, how long it will take, etc. According to this situation, it can be assumed that if there are currently n electric car(s), and $m$ replacement station(s), i is the electric car index, $j$ is the replacement station index, as shown in the figure.

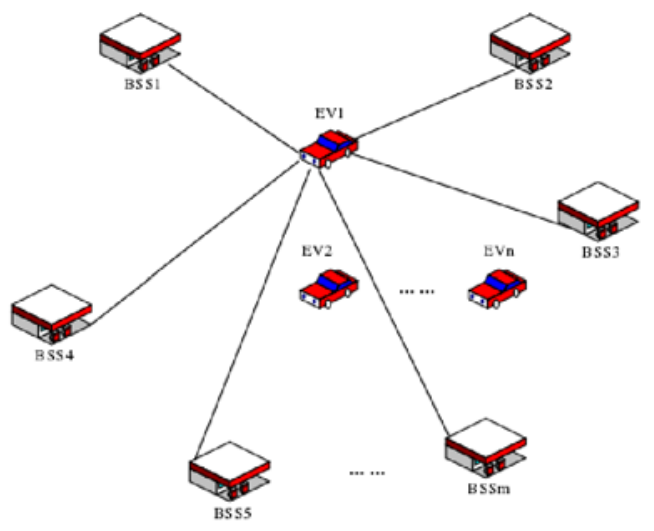

Fig 2.Schematic diagram of electric vehicle drivers' choice of charging stations

Electric vehicle drivers can choose any one of these stations, but in the selection process they will think about a variety of factors, such as distance, power consumption, time consumption and whether they need to wait, etc. Assuming that the current diagram shows that station 1 is the most economical, to reach the station 2 is the closest, exchange station 3 is closer to the next target location, exchange station 4 does not require drivers to queue. The main reason for choosing the station 5 is to consider that the driver will not be caught in traffic jams. According to the above analysis, we can know that drivers tend to prefer the lowest cost, the closest road and the best road conditions on the way. ${ }^{[6]}$ But in normal practice, it is difficult to meet all the above reasons, so the user can only judge according to the current actual situation, and finally choose the most suitable station.

\subsection{Discussion on the congestion of the station}

Congestion of the station is when the driver arrives at the charging station but due to the shortage of electricity in the station, it cannot supply power in time or provide power supply service on time. Although the battery replacement is quick, the long queue will affect the development of the exchange mode. There are many reasons for the congestion of the exchange station, such as the slow construction of the exchange station, which cannot meet the growth of the electric vehicle ownership, the number of station backup battery and the charging power will also limit station cannot provide better service ${ }^{[5]}$ Due to the geographical constraints, as well as the price of the exchange station and other factors, users are prone to pile up when choosing the station, which makes the resources of station distributed unevenly, and the congestion problem occurs while some stations are still in idle state.

In order to alleviate the congestion, increasing the number of stations and expanding their scale, which are limited, should be taken into consideration. In order to make full use of the resources of the station, the most effective solution at present is to perform spatial scheduling for the charging of users, specifically to guide users to choose a more suitable switching station, so that users can be dispersed to solve the problem of congestion in the station.

\subsection{Discussion of electric vehicle drivers under game theory}

When the power of electric car cannot meet the user's travel needs, the user will charge the vehicle, so that the driver cannot drive it in a short time. At this moment, the electric vehicle will have a small critical value, and the user can choose to change the battery or choose a nearby station to change the battery in a relatively small range. And at this moment, the user will focus on the cost and the distance to the change station. The decision flow chart is shown in the following figure. 


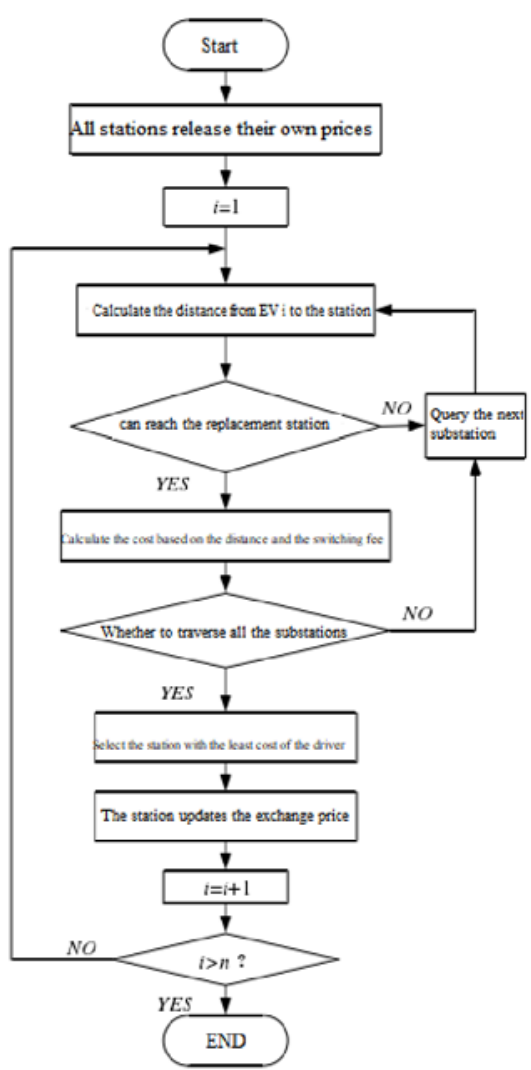

Fig 3.Flow Chart of the User Decision

This paper chooses a discrete-time model, which is divided into several time periods, each of which is fixed for one duration, as a way to meet the needs of power charging scheduling research. The decision of users is often made within a certain time period, and the user goes through several cycles during the whole game process according to Figure 3, but this cycle is limited until finally reaching an equilibrium value and executing the result of the game in the last time period.

\section{Optimization of power charging strategy}

\subsection{Charging strategy based on grid time-of-use price}

\subsubsection{Grid time-of-use price}

The time-of-use electricity price policy is an important means for the current grid to regulate load. The power grid will determine the peak and valley times according to the current and previous electricity load. The electricity price during the peak period is higher and the cost during the valley period is relatively lower. The price incentive is used to guide customers to gradually shift their electricity consumption to the off-peak hours to reduce the peak-to-valley difference, and the electricity price model in the peak-to-valley hours can be constructed as shown in the formula.

$$
p_{t}^{\text {grid }} \begin{cases}p_{p}^{\text {grid }} & t \in T p \\ p_{f}^{\text {grid }} & t \in T f \\ p_{v}^{\text {grid }} & t \in T v\end{cases}
$$

The formula describes the relationship between peak, normal and valley tariffs, i.e. $p_{p}^{\text {grid }}>p_{f}^{\text {grid }}>p_{v}^{\text {grid }}$, however, the pricing of specific peak-to-peak price and the division of peaks and valleys need to be determined based on the reality of the situation.

\subsection{Optimization}

\subsubsection{Objective function}

Switching station is also required to purchase electricity from the grid, the objective of minimizing the charging cost can be known according to the formula. If one hour is taken as the interval, a day can be divided into time periods of 24 hours, and the hourly charging power needs to be solved:

$$
\min \sum_{t}\left(p_{t}^{\text {grid }} P_{t} T\right)
$$

In this formula, $p_{t}^{\text {grid }}$ is the grid time-of-use price and $\mathrm{T}$ is the unit time duration.

\subsubsection{Constraints}

Three constraints need to be considered in the charging cost optimization of the switching station, firstly, the power of charging device, the demand of power exchange and the number of batteries owned in the switching station, as well as the power balance constraint available in the station.

a.Charging power constraint

$$
0 \leq P t \leq P \max
$$

The value $\mathrm{P}_{\max }$ here indicates the maximum charging power that can be provided by the charging devices at the station in time period t. This is related to the number of charging devices available at the station, the charging power, and the number of battery backups, etc.

b.Available power constraint

$$
0 \leq \mathrm{Q}_{\mathrm{t}}^{\text {avi }} \leq \mathrm{Q} \max
$$

$Q_{\max }$ indicates the value of the total battery capacity of the switching station, which is related to the number and capacity of batteries. In order to meet the demand for power charging during the time period, it is necessary to require that the available power at moment $t$ cannot be less than 0 .

c.Available power balance constraint

$$
\sum_{\mathrm{t}}(\mathrm{PtT})=\sum_{t} \sum_{i}\left(x_{i, j} E_{i}\right)
$$

In this formula, $\sum\left(x_{i, j} E_{i}\right)$ indicates the total value of all electric vehícle charging power under time 
period t. It can be understood that the total value of charging in a day in the station is equal to the total value of charging power, and the power available till the end time of the station each day is equal to the value of power available at the beginning moment.

\subsubsection{Calculation}

According to the analysis, the mathematical model, the model of the optimal strategy solution for daily charging of the station, is established. The minimization of formula 2 is the goal, the constraints are formula 3-5. This mathematical optimization model shows linear characteristics, and MATLAB can be used to solve the specific solution.

\subsection{Optimization strategy for wind power consumption and charging}

\subsubsection{Characteristics of wind power output}

As the current most potential clean energy, wind power has a strong volatility and random characteristics. Unlike solar energy, wind power resources can often be applied during the night, which requires the hindrance of wind power grid consumption exists. Electric vehicle load has a greater randomness, so the charging station can use wind power to charge the battery and maximize the benefits.

\subsubsection{Mathematical modeling}

a. Objective function

$$
\min \sum_{t}\left(p_{t}^{\text {grid }} p_{t}^{G} T+p_{t}^{\text {wind }} p_{t}^{W} T\right)
$$

Switching station can purchase electricity from the grid and wind farms, the price of wind power is lower compared to the ordinary grid. The purchase of electricity from the wind power station cannot meet the real demand, the optimization goal is charging cost minimization. Therefore, the formula is as above.

The grid time-of-use price and the wind power timeof-use price are involved in the formula, while $p_{t}^{G}$ is the power of electricity procured from the grid in time period $t$ by the switching station and $p_{t}^{w}$ is the charging power of electricity procured from the wind farm in time period $\mathrm{t}$ by the switching station.

b. Constraints

Four constraints for wind power consumption charging should also be considered.

(1) Charging power constraint for the station $0 \leq p_{t}^{G}+p_{t}^{W} \leq P \max$

In the formula, $\mathrm{P}_{\max }$ is the maximum charging power that can be provided by the charging device of the station in time $\mathrm{t}$.

(2) $W$ ind power charging power constraint

$$
0 \leq p_{t}^{W} \geq p_{\max }^{W}
$$

In the formula, $p_{\max }^{W}$ is the maximum charging power of wind power in time period t. The power is related to the capacity of the wind farm and the transmission capacity of the power supply line where the exchange station is located.

(3) Constraint for available power

$$
\begin{gathered}
0 \leq \mathrm{Q}_{\mathrm{t}}^{\mathrm{avi}} \leq \mathrm{Q}_{\max }^{\mathrm{W}} \\
\text { (4) Balance condition for available power } \\
\sum_{t}\left(\left(P_{t}^{G}+p_{t}^{W}\right) T\right)=\sum_{t} \sum_{i}\left(x_{i, j} E_{i}\right)
\end{gathered}
$$

\section{Conclusion}

At present, the development mode of the exchange station is one of the important factors for the promotion of electric vehicles in the future. Although there are not many research contents for the exchange station, this paper discussed the exchange station scheduling method based on game theory, which included the exchange station scheduling and the exchange station charging research, and proposed a mathematical model according to the realistic needs.

\section{References}

1. Sleptsov Arseniy,Crisostomi Emanuele,Bischi Aldo. Control schemes for district heating substations considering user-defined building ' $\mathrm{s}$ indoor temperature[J]. Building and Environment,2021,191.

2. Ghahremani Baghmisheh Amir,Estekanchi Homayoon E.. Quantifying seismic response uncertainty of electrical substation structures using endurance time method[J]. Structures,2021,30.

3. Mathebula Vonani Clive,Saha Akshay Kumar. Sensitivity and elasticity of multi-channel IEC61850 Substation Communication Networks to imperfect repairs[J]. Sustainable Energy, Grids and Networks,2021,26.

4. Asadi Amin,Nurre Pinkley Sarah. A stochastic scheduling, allocation, and inventory replenishment problem for battery swap stations $[\mathrm{J}]$. Transportation Research Part E,2021,146

5. Ahmad Furkan,Saad Alam Mohammad,Saad Alsaidan Ibrahim,Shariff Samir M.. Battery swapping station for electric vehicles: opportunities and challenges[J]. IET Smart Grid,2020,3(3).

6. Sayarshad Hamid R.,Mahmoodian Vahid,Gao H. Oliver. Non-myopic dynamic routing of electric taxis with battery swapping stations[J]. Sustainable Cities and Society,2020(prepublish). 